\section{G367(P) A SERVICE EVALUATION OF THE TRANSITION HUB: FACILITATING TRANSITION FROM PAEDIATRIC INTO ADULT PALLIATIVE CARE}

G Hosking, M Baba. School of Medicine, Cardiff University, Cardiff, UK

\subsection{6/archdischild-2020-rcpch.315}

Background Increasing numbers of children with life limiting conditions are surviving into adulthood, resulting in more patients entering adult palliative care services. The transition process is crucial for ongoing care and resulting health outcomes. The Transition Hub is a charity-funded, time-limited project providing a holistic one stop service, hosted at adult hospices, to help support children and families in the process of transitioning into adult palliative care services.

Aims To evaluate the Transition Hub service to assess engagement, identify its user perceived strengths and areas for improvement.

Methods Quantitative analysis of data gathered on the existing transition database and qualitative analysis of the service user feedback were carried out to evaluate the impact of the service.

Results $38.5 \%$ of patients invited attended with $66 \%$ of attendees completing the feedback form. Overall, responses were positive, with $100 \%$ of respondents confirming that the Transition Hub addressed their concerns and queries. Identified areas of improvement included altering the time of clinic, more informative invitation letter and additional, varied medical support.

Conclusion The Hub is achieving its aims of guiding patients and families through the transition process. Some achievable improvements can be made to the future Hub service delivery. This model of service delivery during the transition process may be adopted by or of interest to other hospices and trusts.

\section{G368(P) ABSTRACT WITHDRAWN}

\section{G369(P) DEVELOPING PALLIATIVE CARE FOR CHILDREN IN A RESOURCE-LIMITED TRUST - PRELIMINARY CAPACITY BUILDING MODEL AND NOVEL HOLISTIC NEEDS ASSESSMENT TOOL}

EMF Richards, L Pain, A Taylor, FHQ Li, A Dean. Department of Paediatrics, Barking, Havering and Redbridge University Hospitals NHS Trust, Romford, UK

\subsection{6/archdischild-2020-rcpch.316}

Background Paediatric palliative care populations are notoriously difficult to define. There is limited evidence on needs assessments for these patients and families, nor addressing gaps between hospital- and community-based service provision.

Staff within our children's department (which delivers general medical and surgical services, with HDU and daytime haemato-oncology services) highlighted that the holistic needs of these children and young people (CYP) with life-limiting or life-threatening conditions were suboptimally addressed during their inpatient stay. A wide-reaching capacity-building project was therefore undertaken with the purpose of improving quality of care for these CYP.

Process To characterise the service provision for inpatients with palliative needs and identify gaps to be addressed, a

\begin{tabular}{|c|c|c|c|}
\hline Inputs & Process & Outputs & Next Steps \\
\hline $\begin{array}{l}\text { - Staff reflection } \\
\text {-Families' feedback } \\
\text {-MDT working group } \\
\text { •National guidelines } \\
\text { and tools from NICE, } \\
\text { Together for Short Lives } \\
\text {-Internal and external } \\
\text { success stories e.g. } \\
\text { from adult palliative } \\
\text { care, paediatric } \\
\text { oncology }\end{array}$ & $\begin{array}{l}\text {-Estimation of scope } \\
\text { of the problem } \\
\text {-Discussion of current } \\
\text { service provision } \\
\text { - Review of evidence, } \\
\text { guidelines and existing } \\
\text { tools } \\
\text {-Iterative development } \\
\text { of outputs through } \\
\text { piloting and clinical } \\
\text { governance meetings }\end{array}$ & $\begin{array}{l}\text { •Working group } \\
\text { aims } \\
\text { •Novel holistic } \\
\text { needs assessment } \\
\text { tool and standard } \\
\text { operating } \\
\text { procedure } \\
\text {-Departmental } \\
\text { teaching } \\
\text { •Register of CYP } \\
\text { with life-limiting } \\
\text { illnesses } \\
\text { •MDT meeting } \\
\text { with GOSH for } \\
\text { complex case } \\
\text { discussion } \\
\text { •Link nurse role for } \\
\text { children's palliative } \\
\text { care }\end{array}$ & $\begin{array}{l}\text { •Family-led } \\
\text { quality } \\
\text { improvement } \\
\text { research } \\
\text { - Development } \\
\text { and evaluation of } \\
\text { support for staff } \\
\text {-Auditing against } \\
\text { national } \\
\text { guidelines } \\
\text {-Improving } \\
\text { accessibility of } \\
\text { documented } \\
\text { palliative care } \\
\text { discussions }\end{array}$ \\
\hline
\end{tabular}

working group was created and subsequently reviewed many resources (table 1). Members included: clinical lead for palliative care, hospital and community nurses, doctors, managers, oncology specialist nurse, pastoral care team, and learning disabilities liaison.

Results Many outputs were developed and actioned (table 1). Projects aimed to: identify unmet needs of these CYP; signpost families to appropriate services; and develop tools and training to support staff providing palliative care. Collaborative working was central to all aims.

Conclusions Capacity for provision of palliative care is limited in hospital and community settings. Effective coordination of current resources is feasible and promising in a resource-limited trust. This can be achieved by working collaboratively, identifying unmet needs early, and training staff to address these gaps.

\section{G370(P) LEARNING FROM BEREAVED PARENTS: A QUALITATIVE STUDY}

${ }^{1,2}$ A Soman, ${ }^{3} \mathrm{~L}$ Maynard. 'Sheffield Children's NHS FT, Sheffield, UK; ${ }^{2}$ Bluebell Wood Children's Hospice, Sheffield, UK; ${ }^{3}$ East Anglia's Children's Hospices, Cambridge, UK

\subsection{6/archdischild-2020-rcpch.317}

Introduction Children with life-limiting or life-threatening conditions (LLC) and their families face multifaceted challenges. Sensitive, open and effective communication between professionals and families that facilitates shared decision-making is pivotal in ensuring optimal care. Advance care planning (ACP) is widely recommended and is believed to improve outcomes and experience. Practice varies widely within the UK, by geographical region as well as disease.

Aims To explore families' experiences of palliative and end-oflife care, including ACP.

Method This qualitative arm of a mixed-methods study was offered to bereaved parents in the region whose children had died between December 2013 and June 2018. Families known 
to the lead investigator were excluded. Face-to-face interviews were conducted, audio-recorded and transcripts analysed using Thematic Analysis.

Results Nine interviews were conducted; 3 families were excluded as they were known to the lead investigator.

None of the children of the interviewees had formal ACP. A large number of themes emerged, which were collapsed into 31 sub themes, 8 major themes and 3 super-ordinate themes. The superordinate themes were: Communication: A Powerful and Essential Tool to Be Used with Care, Impact of LLC: Beyond the Clinic, and Priorities: Putting Families in Control. Deficiencies in communication - both in its content and form - were the most salient and frequent themes that arose, and interviewees reported lasting negative impact. None of the interviewees reported distress needing intervention as a result of participating in the study.

Conclusions Sensitively conducted qualitative research with bereaved families is safe and feasible. Formal ACP and early prognostic discussions are not yet part of routine paediatric practice in the region. Formal ACP and early integration of palliative care are likely to positively impact subjective experiences as well as outcomes such as realisation of preferred PoD. This study was limited by diagnostic heterogeneity and socio-cultural homogeneity of the sample and potential recruitment and recall bias.

Further training of paediatric professionals in communication skills and ACP, and improved access to specialist PPC are recommended. Further research is needed into a. the impact of ACP in different patient groups and b. to professionals' perceptions and barriers.

\section{G371(P) BARRIERS AND FACILITATORS TO PAEDIATRIC SYMPTOM MANAGEMENT AT END-OF-LIFE: RESULTS FROM A SYSTEMATIC REVIEW AND META-ANALYSIS}

${ }^{1} \mathrm{~K}$ Greenfield, ${ }^{1} \mathrm{~S}$ Holley, ${ }^{1} \mathrm{DE}$ Schoth, ${ }^{2,3} \mathrm{E}$ Harrop, ${ }^{4} \mathrm{~J}$ Bayliss, ${ }^{5} \mathrm{RF}$ Howard, ${ }^{6} \mathrm{M}$ Johnson, ${ }^{1,4} \mathrm{C}$ Liossi. 'School of Psychology, The University of Southampton, Southampton, UK; ${ }^{2}$ Helen and Douglas House Hospices, Oxford, UK; ${ }^{3}$ John Raddliffe Hospital, Oxford University Hospitals NHS Trust, Oxford, UK; ${ }^{4}$ The Louis Dundas Centre, Great Ormond Street Hospital for Children NHS FT, London, UK; ${ }^{5}$ Department of Anaesthesia and Pain Medicine, Great Ormond Street Hospital for Children NHS FT, London, UK; ${ }^{6}$ Patient and Public Representative, NIHR Pain and Palliative Care Clinical Studies Group-Children, London, UK

\subsection{6/archdischild-2020-rcpch.318}

Background Managing symptoms, including pain, at end-of-life for infants, children and young people is challenging due to the broad spectrum of life-limiting or life-threatening conditions, and also differing care needs depending on patients' age. The UK National Institute for Health and Care Excellence (NICE) highlights pain management in paediatric palliative care as a research priority. A clearer understanding of these challenges could inform the development of effective interventions.

Aims We aimed to conduct a mixed-methods systematic review and meta-analysis investigating the barriers and facilitators experienced by patients, carers and healthcare professionals managing symptoms in infants, children and young people at end-of-life.

Methods PROSPERO, Cochrane Library, CINAHL, MEDLINE, PsycINFO, Web of Science Core Collection, ProQuest Dissertations \& Theses Database, Evidence Search and OpenGrey were searched from the inception of each database for qualitative, quantitative or mixed-methods studies that included data regarding barriers or facilitators to paediatric end-of-life symptom management from patients, family carers or healthcare professionals. Search terms were derived from a thorough reading of relevant literature and in discussion with a medical librarian. Data extraction, quality appraisal, and narrative thematic synthesis were undertaken for all eligible studies, with meta-analysis also performed where data permitted.

Results We identified 34 quantitative, 19 qualitative and 17 mixed-methods eligible studies of medium-low quality (assessed using GRADE-CERQual). Themes were generated around the barriers and facilitators experienced by family carers (Treatment efficacy, Treatment side-effects, Healthcare professionals' attitudes, Hospice care, Homecare, Families' symptom management strategies) and Healthcare professionals (Medicine access, Treatment efficacy, Healthcare professionals' demographics, Treatment side-effects, Specialist support, Healthcare professionals' training, Health services delivery, Homecare). Only one study included patients' views. Caring at home for a child was reported as a barrier to symptom management by between 22 and 24\% of participants (pooled weighted mean of $0.244, \mathrm{k}=3, \mathrm{n}=197,95 \% \mathrm{CI}=$ 0.177-0.326).

Conclusions This review highlights the need for clear communication within and between healthcare professionals and families; more training for healthcare professionals and improved symptom management planning, including anticipatory prescribing. There is an urgent need for more research into children and young people's experience of symptom management at end-of-life.

\section{G372(P) A SYSTEMATIC REVIEW OF BREAKTHROUGH PAIN ASSESSMENT TOOLS AND THEIR PSYCHOMETRIC PROPERTIES}

${ }^{1} \mathrm{~K}$ Greenfield, ${ }^{1} \mathrm{~S}$ Holley, ${ }^{1} \mathrm{DE}$ Schoth, ${ }^{2,3} \mathrm{E}$ Harrop, ${ }^{4} \mathrm{~J}$ Bayliss, ${ }^{5} \mathrm{~A}-\mathrm{K}$ Anderson, ${ }^{6} \mathrm{RF}$ Howard, ${ }^{1,4} \mathrm{C}$ Liossi, ${ }^{7} \mathrm{M}$ Johnson, ${ }^{4} \mathrm{D}$ Rajapakse, ${ }^{8}$ LK Fraser, ${ }^{2} \mathrm{C}$ Mott, ${ }^{9}$ I Wong. ${ }^{1}$ School of Psychology, University of Southampton, Southampton, UK; ${ }^{2}$ Helen and Douglas House Hospices, Oxford, UK; ${ }^{3}$ John Radcliffe Hospital, Oxford University Hospitals NHS Trust, Oxford, UK; ${ }^{4}$ The Louis Dundas Centre, Great Ormond Street Hospital for Children NHS FT, London, UK; ${ }^{5}$ Royal Marsden Hospital, Sutton, UK; ${ }^{6}$ Department of Anaesthesia and Pain Medicine, Great Ormond Street Hospital for Children NHS FT, London, UK; ${ }^{7}$ Patient and Public Representative; ${ }^{8}$ Martin House Research Centre, University of York, York, UK; ${ }^{9}$ School of Pharmacy, UCL, London, UK

\subsection{6/archdischild-2020-rcpch.319}

Background Breakthrough pain is commonly experienced by both children and adults with cancer, and also by patients with other terminal conditions, including those approaching end-of-life. Management of breakthrough pain is often insufficient, which could be due in part to a current lack of validated assessment tools. The aims of this systematic review are to (1) identify all available instruments measuring breakthrough pain in infants, children, adolescents or adults, and (2) critically appraise, compare and summarise the quality of the measurement properties of each identified instrument using established COSMIN criteria.

Methods Two searches were carried out, one corresponding to each aim of the review. For both, the Cochrane Library, PROSPERO, EMBASE, CINAHL, MEDLINE, PsychINFO, Web of Science Core Collection, Google Scholar, the ProQuest Dissertations \& Theses Database, Evidence Search and OpenGrey were searched from the inception of each database to October 2019. Search terms were derived from a thorough 